\title{
Tackling strangeness while conducting ethnographic fieldwork by an anthropologist in Africa: a narrative from Cameroon
}

\begin{abstract}
Background: This paper presents the experience of doing ethnographic fieldwork in a culture believed to be yours, yet strange to you.

Aim: The aim was to probe into the daily interactions of people living with diabetes in two health districts and understand the intricacies of fieldwork in a home setting in an African context.

Method: A two-year fieldwork was conducted in Yaounde, the capital city and Bafut a Rural Health District in the Bamenda Grassfield of Cameroon from 2001-2003. Participant observation was used for data collection, pulling in a range of research methods to explore and describe people and events at different levels. Sampling was strictly in a qualitative style whereby methods, events, people, places and time guided issues and progress in fieldwork. The data were collected in fieldwork conversations, participation in fieldwork events, interviews, focus group discussions, extended case studies and biographies. The analyses were thematic.
\end{abstract}

Findings: The findings are presented in five main themes that describe the essence of the experience with the overall theme of Growing through experiencing strangeness in ethnographic fieldwork. The first theme portrays how I met and tackled the multiple initial and subsequent challenges. One of the challenges, described in the second theme, was being an outsider and needing to be let in. The third theme explores the language issue, while the fourth theme is the different fieldwork culture. The fifth then illuminates how I finally overcame the intricacies of strangeness at home.

Conclusion: The findings and their context suggest the importance of playing an outsider and insider role and how language and culture are inseparable entities in conducting and shaping ethnographic fieldwork and the ethnography produced.

Keywords: ethnography, strangeness, fieldwork, anthropologists, tackling, cameroon, africa
Volume I Issue 5 - 2017

Paschal Kum Awah

Department of Anthropology, Faculty of Arts, Letters and Social Sciences, University of Yaounde, Cameroon

Correspondence: Paschal Kum Awah, Department of Anthropology, Centre for Population Studies and Health Promotion, Cameroon, Tel +237 6778I2028, Email awahpaschal@yahoo.fr

Received: December 19,2016 | Published: August 24, 2017
Abbreviations: ANSA, action on non-communicable disease in sub-sahara africa; NCD, non communicable diseases; PHC, primary health care

\section{Introduction}

Anthropologists have developed methodologies for gathering data, testing hypothesis and theories to understand human diversity. These methodologies are used in naturally occurring human societies and cultures. They may apply these methodologies to understand how human societies adapt to controlled situations set up by other fields of study. Anthropologists rely on ethnographic method and crosscultural comparison. ${ }^{1}$ The ethnographic method is the gathering and interpretation of information based on intensive first-hand study of a particular culture. The product or report of the data gathered is ethnography and the act of conducting the study is also ethnography. Ethnography is fieldwork and also the product from fieldwork. All the activities and specialties that make up cultural anthropology are grounded on ethnography. Ethnography is both a major source of anthropological data and also a major part of anthropologists' experience. I start by discussing ethnography then will proceed to discussing ethnographic fieldwork that I conducted in Cameroon some ten years ago and what it takes to do ethnographic fieldwork in Africa as an African.

Ethnography is a written description and analysis of the culture of a group of people based on fieldwork. ${ }^{2}$ Fieldwork is the first-hand, intensive, systematic exploration of a culture. ${ }^{1}$ Although fieldwork entails many techniques, the core of Anthropology fieldwork is participant observation. Participant observation is the technique of gathering data from human cultures by living among people, observing their social interactions on an ongoing daily basis and participating as much as possible in their daily lives. ${ }^{1}$ The field experience result in an ethnography, which is an in-depth description and analysis of a given culture. $^{3}$

This paper presents the lived experience of a medical ethnographer working at Yaounde (urban) and Bafut (rural) hospitals and communities in Cameroon from 2001-2003. The ethnographer conducted research on how people with diabetes went about treating themselves. The focus is on the perspectives of doing ethnography in a culture that is considered to be yours yet strange to you. That is, doing anthropology at home. ${ }^{4-6}$ The aim is to document the understanding of an ethnographer's experience with the purpose of contributing to 
the discourse about doing anthropology at home, as a native, in Africa within a medical research context.

\section{Material and methods}

\section{The local context of the study}

Two settings characterize this ethnography: Yaounde and Bafut. Yaounde is the capital city of Cameroon located in the Centre Region in a part of what is known as Francophone Cameroon. Located in the central low plateau of Cameroon, the Yaounde area has an undulating relief ranging from 300 to 700 meters high. Though the topography of the central plateau is relatively low, Yaounde harbors the highest elevations of over $1500 \mathrm{~m}$ in the centre plateau. These elevations have earned Yaounde the title of 'the town of seven hills', with Mounts Mbankolo and Febe being the highest. The rains here are conventional. Unlike most of Cameroon, Yaounde has four seasons: one short and one long rainy season and one short and one long dry season. The soils are mainly lateritic and clay, hence producing sticky mud on earth roads. Though some secondary equatorial forest can be seen at the outskirts of the town, very little of the original equatorial forest is left, because of the unsustainable nature of exploitation and rapid urbanization of the town. Yaounde has undergone changes in its official languages from German (1885-1916) to French (1919-1960) and post independence (1961-date).

On the other hand, Bafut is located in the Anglophone North West Region of Cameroon, specifically in the Bamenda Grassfield. Bafut was once a forested area but most of the forest has been destroyed leaving a sheet of palm trees and patches of woodland covering the rolling hills. This territory underwent two different colonial administrations: German (1884-1916) and British (19161961) and ended up inheriting the English Language as the official language. However, both districts became independent in 1960 and the reunification of East (Francophone) and West (Anglophone) Cameroons led to the forming of a federated state (1961), then a United Republic (1972) and the Republic of Cameroon (1984). The judicial and educational policies of Francophone and Anglophone Cameroon greatly contrast, with the Francophone territory adopting French civil and educational frameworks while the Anglophone territory adopts the common law and British educational frameworks. These two sites are typically urban and rural, contrasting the urban and rural cultural ecologies.

\section{The context of research participants}

In contrast to conventional scientific methods, ethnography is rarely experimental or predictive in aim. Instead its rationale is to avoid reductionism by building up rounded descriptions from the flow of daily life, in order to highlight complexity in the multiple and often competing perspectives displayed in any social milieu. ${ }^{7}$ Rather than looking at a small set of variables and a large number of subjects ("the big picture"), the ethnographer attempts to create a detailed understanding of the circumstances of a relatively few people being studied intensively. ${ }^{2,8}$ For this study, observations, conversations, interviews, focus group discussions, biographies, case studies and documentary evidence were the range of tools used in field work.

Twenty patients and their families, ten each in Yaounde and Bafut, were selected for close follow-up. Eight families were visited more or less daily over the extended periods of the fieldwork in each of the sites; the rest were visited weekly, sometimes more than once. This was more intensive in the rural than in the urban district. The mean number of family members was seven. The duration of visits ranged from 30 minutes to two hours. Meanwhile, more than two hundred patients were part of the network of observations in the clinics and in the communities where they lived. That is, all patients at the sampled clinics formed part of the observation network within the clinic during consultation sessions and out of the clinical settings. Ten traditional healers were the main frame of traditional healers observed regularly, at least daily for some and biweekly for others. Twenty-four diabetes consultants were the main biomedical health care providers (BHCP) observed in clinical encounters, though the activities of others within these care units were closely monitored. The wider communities of these health districts were part of the daily field work observation.

\section{Negotiating my way in selecting research participants and gaining access}

In Yaounde, I initially selected patients in the clinics where they routinely consulted with a view to following their progress over the course of the year's fieldwork. A nurse introduced me to the patients during a diabetes clinic session as someone who was researching on diabetes. Patients were initially told that someone with a special interest in diabetes would be doing research in the clinic. Their expectation was that they would see me in consultation rooms and in the clinic setting. I introduced myself in individual conversations by saying: 'I am called ... and I'm working on diabetes. I am learning how people live with diabetes. I would like to observe how you manage with diabetes day by day and I'd like to talk to you about it. Would you mind if I visit you at home as well?'

Most of the time, people readily agreed. Some participants assumed initially that I was a medical doctor - so accepting that I could visit them on a regular basis was also perhaps going to be a benefit and provide some services that were not provided in the clinics. Once contact was made and some trust built up, we would meet at clinic appointments, but also at their homes or in bars and other social events. Subsequently, as my presence became more familiar, other people, other than the initially targeted ones, asked me to visit them too and I decided to visit the homes of those that insisted. These visits were often useful and extended my understanding of how they were trying to make sense of my person and the diabetes that they lived with.

In my previous experiences, it was normal practice in Bafut to announce in churches any new research activity or the arrival of a researcher and to use the occasion to appeal for collaboration. Robert Pool's arrival in Tabenken was announced in local churches. ${ }^{9}$ I declined this approach, however, opting to allow people to 'discover' me for themselves in Bafut but allowed to be introduced to the local leaders, The Fon and the divisional officer. After my time in Yaounde, I was aware that a church announcement might paint an unrealistic picture of which I was and raise people's expectations. In particular, I did not want to accentuate any more than was inevitable an identity as 'doctor'. In Bafut, I worked with two clinics, but identified most of my patients with the assistance of a male nurse in one of them. The nurse later became one of my gatekeepers. I made a choice based primarily on patients' accessibility. Moreover, in order to avoid delays during the initial phase, I opted to visit patients in their homes, because clinic activities were not as regular or as organized as those in the Yaounde clinics. In every instance, I was accompanied and introduced as a doctor working on non-communicable diseases (NCD). I then 
explained who I was and my objective to each individual. This initial 'meeting the patients at home' approach turned out to be very helpful because it introduced me to patients and families at the same time.

It was through patients and their families that I initially gained access to certain community events and indeed to the wider community. I found this less difficult in Yaounde, because I lived in the city. Even so, there were new things I had to learn like staying up to late hours in restaurants and bars, if I was to witness properly people's eating and drinking habits. This was not like me. And when people started seeing me regularly in these places, they seemed surprised also. Yet because the nature of community is so different in urban and rural settings, my presence rarely provoked many questions in Yaounde. In Bafut, by contrast, my presence was swiftly known by all and sundry and people needed to place me. My previous work with the Action for Non-communicable Diseases in Sub-Sahara Africa (ANSA) project was crucial here and I was helped also by the influence of the District Medical Officer for Bafut. This health research background legitimized me, but was also to prove a constraint later, as I sought to extend my fieldwork to traditional healers. Moreover, no one can come to Bafut for an extended stay and fail to legitimize his/her presence by getting the tacit approval of the Fon and the wider palace hierarchy and I was no exception. It was a compulsory step to introduce myself to the Fon. One of his brothers was my usual point of entry when I sought to meet the Fon subsequently. But Muntoh (Prince) had always to liaise with one of the Queens to arrange an appointment, making such visits at least a two-step process. This was not necessary when visiting the palace to attend traditional ceremonies open to all for example, Moumetaah (Country Sunday). But whether an intermediary was necessary or not, each visit necessitated bearing a gift as my field notes described my meeting with the Fon.

'What can I do for you?' Muntoh replied, 'Mbee (a respectful form when meeting the Fon as you cannot answer with a straightforward 'yes' or 'no') this is Dr Awah. He has come from Yaounde. He works in the NCD programme. He has come to greet you and to tell you that he will stay here for one year studying diabetes. He is better placed to inform you about his programme'. I introduced myself as follows: 'Mbee. I am Awah, a social scientist working with the NCD programme. I am a student with the University of Newcastle in England. I shall be staying in Bafut for a year to study how people try to cope with diabetes within their families and in the entire Bafut community. Once in a while I will visit the palace to see how things work here and discuss with you".

'You say your name is Awah?'

'Mbee', I replied.

'Good! You come from where?’ He continued.

\section{'From Kom', I replied.}

'I see. And you bear Awah. Have you checked around to see if you don't have a family in Bafut? That name is Ngemba so might be Bafut. You are welcome to Bafut. You are a Grassfield person, it should not be very strange to you. We shall be available for you to consult at anytime. Make sure that you inform me whenever you need me. I will always help'. (Fon, Bafut)

Muntoh negotiated many of my contacts with the Fon and I had similar and varied conversations with the Fon during my one year in Bafut. As fieldwork evolved, the gatekeeper role of Muntoh started waning. I had the Fon's contacts and we could arrange to meet for further conversation. But at every instance he was accompanied by one of his guards who stayed at a distance while we shared a conversation. Two important access gaining aspects emerge. Firstly, it is the processes of gaining access, as discussed. Our data illustrate that gatekeepers and/or informants can be more empowered when deciding to grant access or not but become less powerful once access is gained. However, they are able to renegotiate this power. A second aspect of the ethnography level is which events take place and meanings and relevance attributed to these events in the context of the ethnography through which I have access.

\section{Ethics clearance and informed consent}

The researcher set out to explore the treatment of diabetes in Yaounde and Bafut. The choice of Yaounde and Bafut as research settings arose out of previous work on non-communicable diseases in these two areas. Ethical clearance for the work was provided by the National Ethical Committee. But before starting fieldwork, authorization to conduct fieldwork was obtained from the Ministry of Scientific and Technical Research and Ministry of Health. Once I had administrative clearance at higher level, I set out to obtain clearance at peripheral levels where the study sites (Yaounde and Bafut) were located. I had worked as project manager for Action for Non-communicable Diseases in Sub-Sahara Africa (ANSA) and interacted with some staff at clinics in both settings. Informed consent for patients and clinic staff was documented at recruitment clinics, but informed consent for family and community members and traditional healers was verbal.

\section{Results and discussions}

\section{Becoming an outsider and the need to be let in}

Here, I give a self-scrutiny on my position in this fieldwork; examining the pros and cons of doing it in my own country ${ }^{10-15}$ and in these two sites. The advantage I had doing this fieldwork in my country was that I knew where to go for the clearance and I had my arrangements go through easily. I knew a good number of gatekeepers at the onset of my research. My knowledge of the four languages used in carrying out daily business in Cameroon was an additional advantage to me. These assigned me a complex status. My complex status enabled me to take a distant middle position to gain access, study, understand and interpret this ethnography as an insider and outsider using 'strange' scientific approaches with which people could not identify. These complex positions and roles provide a more complex comparative ethnography than a completely foreign or even a completely native person. However, I keep the anthropological tradition intact, respecting the privacy and voices of the people who produced this knowledge. ${ }^{16-18}$

The challenges I had was that I had family responsibilities to tackle while I was in my country. When I was in Yaounde, I could take a day or two off to handle issues concerning my family. If I were away, other people would have been more concerned with this. Also, my research subjects had a lot of expectations from me. I tried to satisfy some of them, because not doing so could have affected my fieldwork. In such cases, I avoided direct discussion of the problem and the research subjects got the solutions by themselves using the advice that I gave. When I settled to conduct fieldwork in Bafut, I had a taste of staying away from home and doing fieldwork. There was no family to cater for so I had to meet new people and negotiate how to live with them. In Yaounde, I needed to restrict my staying away from home because 
of the threat of crime but in Bafut many people stay out of their homes to any hour of the night without nursing any fear of being attacked by thieves. This permitted me to stay out for as long as people could stay awake. These changes in lifestyle also introduced me into more drinking than had been adopted during fieldwork in Yaounde. But this gave me more insights into material to work on.

Doing ethnography as a Cameroonian in Cameroon meant that I already had a notion about certain things ${ }^{9,14,9-21}$ like being proficient in four languages widely spoken in the settings and in the administrative procedures. Some foreign fieldworkers have visited Cameroon more than once to get issues of administrative and ethical clearance done before they could start fieldwork. I knew some of the key people in authority so I did not suffer delay. Another Cameroonian, not knowing these channels, would have had things done for him normally but not with similar speed. In the field in Bafut my name Awah, ${ }^{7}$ served as a significant integrating device as people first identified me as possibly being Bafut or a sister tribe around until I clarified that I was Kom.

\section{Dilemma of someone considered in the West as an insider and at home as an outsider}

Insiders are the members of specified groups and collectivities or occupants of specified social statuses, Outsiders are the non members. ${ }^{22}$ The representation of an insider and outsider from the Western perspective is broader than that defined by the African. Western social scientists consider doing fieldwork in one's continent as doing fieldwork at home. ${ }^{2}$ Being away from home means being in another continent. In Africa, one's home is his village, tribe or ethnic group. Any other context beyond this is strange. This geographical and cultural settings belong to another, so outside of my native context. For that reason I had to gain access as an outsider. I was doing fieldwork in settings of Cameroon being culturally different from my native ethnic group. This means that I was doing fieldwork out of my native community. I was regarded in Yaounde and Bafut as a stranger similar to what other Anthropologists ${ }^{9,23,24}$ faced in their fieldwork. In a rural setting like Bafut, most of the rituals conducted here were completely new and strange to me. Even Bafut people who had stayed in Kom used to say, "In Kom, this is the way it is done. In Bafut this is how we do it". I had to learn very new and strange behaviors that I had never come across. Talking about fieldwork experience, Ellen ${ }^{8}$ holds that doing research in one's country is equivalent to doing research at one's home or in one's community. ${ }^{10-12,20,24}$ This is not quite obvious with my case or that of other researchers conducting research at home. In both Yaounde and Bafut, I was a stranger to the land and people. I was called Ntobo (stranger) by the Ewondo in Yaounde and in Bafut, Mou-Kom (the child of Kom) all meaning 'stranger'. So, ways of life were different and each of them had its own interpretation to issues. The global way of doing things and the mixing of cultures has created lots of resemblance in behavior and the interpretation of things. For example, one of the main cults (Chong) in the Bafut palace never used to exist in Bafut until it was brought from the Aghem Kingdom by a girlfriend of one of the princes.

But, a country in the African context is quite different from a country in the Western context, given that what obtains as 'country' in the West is equated with a tribe or ethnic group in Africa. For example, the notion of the head of a clan/tribe is understood as being a 'King' in his own right. The boundaries between countries, drawn by colonial powers do not necessarily pull together the different cultural traits to make people be regarded as natives or strangers in the same way as in the West.
However, I tended to grow sympathetic at certain times when I encountered a sad situation. I tried to suggest ways to help solve some critical problems of which I was part. This in a way could modify a certain pattern of behavior that someone would have adopted if she faced a difficulty. A foreign fieldworker would have merely gone about his/her business and allowed the situation to take its natural course. A good example is that of a patient, who was going to spend two months without receiving insulin because the family could not provide. They complained to me and I bought her the insulin that she took for two months until the family could provide. However, if I did so it was because subjects always had expectations from me as I interacted with them. It shows that fieldwork is an exercise of exchange between a fieldworker and the participants. Age, class and other functional activities can attribute you an outsider or insider position irrespective of your tribe and place you in a situation of weak and strong negotiator. But these positions are constantly changes as fieldwork evolves.

\section{The strange scientist-doctor: shifting names and shifting roles}

Here I examine what it is like doing ethnography in a culture that understands health research to be fundamental scientific research. I was seen as a rather strange kind of scientist. With my background training, it was challenging for me to switch over and embrace the demands of participant observation but I had no other option but to embrace the art related to it? Clinic staff initially had the impression that I was a medical doctor. One day some nurses referred the Fon's wife to me when no doctor was present in the hospital to attend to an emergency. When the nurse came to my home, I took time to explain what I was doing to her and moved out to search for a doctor to attend to her. I used my mobile phone to locate a network and call one of the doctors to announce the emergency. This was embarrassing and could have cost me my stay in Bafut had there been any confusion about my role. From that day, the nurse always found time to explain issues about Bafut culture to me whenever we met. Since I did not consult like the two medical doctors of the district hospital, people referred to me as the doctor in charge and specialized in NCDs only. Three months later in my fieldwork, people found out that I was more interested in diabetes patients and their families so they gave me the title of 'diabetes doctor'. To them, I was the boss of the two medical doctors in that disease. When I became very interested in the traditional medical practices and was frequenting traditional healing homes and ritual sites, people were confused and considered it to be strange.

In the two sites, people thought that I might be trying to study what the traditional healers use in curing diabetes so that those leaves could be refined and used in the hospital. In other words, they assumed my work must have a scientific purpose and be aimed at 'discovery' of new treatments. To people, it was a good idea to find someone studying these medicines that may provide a cure. People questioned why I was very close and down to earth with the people in the community and the medical doctors were not. They appreciated my openness and were always eager to guide me to where I could get information.

Doing ethnography in a culture that understands health research to be fundamental scientific research looked very challenging to me. Initially, people thought I was going to stay in the laboratory on a microscope or be consulting patients. The most they saw me do in the clinic was to sit in when consultations were going on and watch 
patient consultations, take notes and ask questions to the staff and some patients. If I shared a seat with patients who could read and write, they always peeped into my notebook to figure out what I was writing. When they discovered that I was just taking an account of what was being said and done, they went about their business. Initially this looked strange to the patients but they later came to understand that I was writing notes for me and that had no repercussions in their lives. The patients kept attributing different roles to $\mathrm{me}^{25}$ just as happened with Pool $^{9} \&$ Sandelowski. ${ }^{26}$ Initially, I was viewed as a medical doctor but when they never saw me consulting as clinic staff did, they changed the appellation. It did not take long for patients in Biyem-Assi to understand my role. In Bafut it was a gradual process.

\section{Local power relations}

These relationships are set within the ethics of power and giving back to the field. There are no hard and fast rules about what, how much and to whom field researchers should give but evolving approaches with progress in fieldwork. Below, I discuss the negotiation of power relations in the field showing the context which I was seen as of higher status than those I mixed with and the context where I was not very powerful. I also reflect on how local power relations shaped my access and the perspectives that I present.

Power relations in the field are mixed and must be negotiated as circumstances permit. ${ }^{16,17,19}$ They are not permanent in so far as exchanges take place which may alter perspectives on either side. I did not have equal status with every person in the field. There were some participants who had higher statuses so I had to beg for any relationship. For example, whenever I had to visit the Fon, I needed to make an appointment and use a gatekeeper at two different levels before I could reach him. I could chat with him within limits for he had the powers to allow me do fieldwork or reject my request. Once he was available, I maximized the time that I had to spend with him. Whenever I met him in public I watched and listened to him very closely because it was difficult seeing him again. Other people of very high statuses were the Director of Research and all the district medical officers (DMO). They had authority that could stop whatever I was doing in the field but I had long-standing relationships with them to the extent that they were always ready to assist me in times of need. I decided to keep very warm relationships to make sure that my stay in the field remained hitch-free. Generally, I did not have an inferior status with most patients, as they knew that I was doing research on their diabetes and this could lead to improving the quality of care given them. They valued my presence amongst them. High profile patients in Yaounde and at Bafut, whom I thought could be less receptive because of their positions in society, turned out to be closest to me.

I had been given the impression that traditional healers were the most difficult people to approach and deal with because of their superior positions in society but experience proved that they were the most collaborative. Whenever I approached them for the first time, fear and anxiety surrounded me but the reception they gave me was friendlier than other people imagined it might be. Instead, they regarded me as a high profile person comparable to the medical doctors around. The expectation was that since I was dealing with them and the medical doctors, I could be a possible link between them and the medical doctors. They turned out to be the most easily accessible group.

The act of giving back is, for some, a direct response to a history of colonial scholarship that exploited study participants and communities by taking or 'stealing' their knowledge without acknowledgement or any kind of compensation. ${ }^{27}$ Studies in Africa seek to dwell on ways in which research interventions can be self-determined and/or more inclusive, useful and empowering for the communities that are a part of the intervention. ${ }^{28,29}$ For others, the notion of giving back falls within the framework of research ethics ${ }^{30}$ whereby institutional review boards (IRBs) have been established to ensure ethical research practice, borne out of a dark history of (primarily medical) research which took advantage of vulnerable populations like prisoners, children and the mentally disabled. ${ }^{30}$ These guidelines provide rules about remuneration, selection for study and treatment of human participants in an effort to reduce coercion and inequity in research. Yet as most practicing researchers know, especially those of us who approach research from an anthropological perspective, research ethics is about more than adherence to institutional protocols. It is all about ensuring personal integrity while conducting fieldwork and respecting basic ethical principles to protect research participants. At the very base of it, most of us want to be able to appreciate our field research participants in meaningful, useful and culturally appropriate ways.

\section{The challenge of learning another language}

Doing Anthropology fieldwork in a setting requires that the researcher learns and masters the language of the setting to permit the researcher to develop insides in the emerging themes. ${ }^{31-33}$ During fieldwork, I relied on four languages: English, French, Pidgin and Bafut. The first three of these are languages I have spoken for most of my life. But although I come from the Bamenda Grassfield, the Bafut language was new to me. I started to study Bafut by buying the Bafut Alphabet from the Summer Institute of Linguistics. When I travelled to Bafut for fieldwork, I decided to purchase a book on learning to read and write Bafut and tried to practice it with people. In July 2002, during the summer holidays, I attended a Bafut language course. Most transactions and interactions in public places in Bafut were conducted in Pidgin, even among Bafut people; but at home, in rituals and traditional ceremonies, the Bafut language was used. Moreover, in the clinics the nurses used both Pidgin and Bafut to consult their patients. And during traditional Bafut kingdom ceremonies (such as the Takumbeng ritual) or in the palace Bafut was used. In bars, a mixture of Bafut, Pidgin and English was typically spoken. Whenever possible I asked for clarification for anything that I did not understand, ensuring that more than one person explained to me.

In Yaounde, most of my research was carried out in French and English, supplemented by Pidgin. In the clinics where I had most of my clinic encounters, Pidgin was used for consultations and health talks with translations into French. With such ethnic diversity in the city and the possibility that within a family the parents might speak a mother tongue which their children could barely understand, the use of local languages did not arise. My own interviews or conversations were largely done in English or French, while in the case of traditional healers, Pidgin tended to be more useful. Transcripts and notes taken in other languages were translated into English. ${ }^{7}$

\section{Relations and communication}

While I sought to mix widely in both settings, like anthropologists everywhere, I found myselfat moments dependent on gatekeepers ${ }^{9,16,18,23}$ who facilitated, but also influenced the access I sought to individuals, groups or specific settings. Some gatekeepers I could choose; others simply emerged largely by chance (or so it seemed). They featured in both Biyem-Assi and Bafut, but much more obviously in the latter, 
where entry to the palace depended on formalized gatekeepers in a way not apparent elsewhere. I have already referred to the way in which, via a Prince and then a Queen, an audience might be obtained with the Fon. In both places, clinic staff performed a gate-keeping function in initially helping me to meet patients. Further, initial progress in seeking to establish social relationships with traditional healers depended on the introductions and reassurance (for both of us) that a gatekeeper could provide.

In Bafut, this process proved more difficult than I had expected. I asked one particular key informant (a nurse) if he could arrange a meeting with a traditional healer. Two weeks went by before he made any effort. When he returned, he told me that some money would be required before any meeting was possible. I decided to try a different tact and with the assistance of a Prince, I made contacts with one traditional healer, who allowed me to observe him in practice. That gave me the courage to try and meet others.

When I recounted my experience of meeting the first traditional healer to the nurse, he offered to take me to an Islamic traditional healer. I would have gone alone but on my first attempt to meet him, the compound looked frightening. I saw a knife nailed on the floor and another to the ground directly at the entrance and two spears crossing the doorpost. Worse still, the door was wide open without a person around. When I managed to make my way out of his fence, I decided to seek the nurse's company. Later, when I met the Islamic traditional healer, I discovered that we knew of each other but had never had an opportunity to talk to each other. The Islamic traditional healer told me how he had made efforts to talk with me but a good opportunity had not arisen. He supported the impression I had that nurses were reluctant to put me in contact with other traditional healers because the nurses feared and respected traditional healers and also considered that these healers may bewitch me; that is; use their powers against me. Since nurses were the first group of people with whom I interacted in the community, their feelings were obviously expressions of concern for my security more so because they did not understand the processes involved in anthropological fieldwork.

In Yaounde I used other traditional healers as gatekeepers to contact others snowball approach. ${ }^{7,26}$ But this type of collaboration was completely absent in Bafut. In other cases I turned up where I saw a signpost indicating the presence of a traditional healer and introduced myself. You could hardly hear a traditional healer talking about another. If he did, it was to condemn his practice. It was a life of competition, hatred and secrecy. Many anthropologists who have worked in the Grassfield like Robert Pool ${ }^{9}$ used assistants. I did not find that necessary but resorted to making use of the gatekeepers in the field. Pool ${ }^{9}$ had at one stage in the field started having misunderstanding with his assistant because people did not want his presence around anymore especially as he did not come from that village. If I were to have an assistant in Bafut, it would have been the nurse, but I would have run into problems because he comes from a part of Bafut that challenges the authority of the Bafut Palace. The nurse had at one time been a target of political problems linked to the Bafut Palace and so had to escape being beaten. He could not take me to certain places because people were suspicious of him.

There was no problem in using clinic staff as gatekeepers to meet patients. In fact, they served as the best way for me to have first contacts with the patients at the clinics. But using them to meet traditional healers and authorities was the most difficult thing that I found. I decided to approach them myself. At one time, I felt that the nurse had become inquisitive and wanted to know what I was doing with all the information that I was collecting. I decided to reveal some to him so that it should not be a barrier for him to be open to me. In August of that year, I received a visitor from England and accompanied him to Yaounde. Before departure, I left one of my transcripts and fieldnotes on my table and then locked up the audiocassettes and the rest of the fieldnotes and transcripts in a drawer. I handed my door keys and recorder to the nurse assuming that he will try to search my home to read what I write. On my return, there was evidence that he took time off to read some of the transcripts and fieldnotes. He was asking me questions from issues found in my notes and always reminded me to take my field equipment when I was visiting with him. He had taken one of the unused audiocassettes and went taping interviews with his patients in the clinic. He brandished the cassette and told me that he had good material for me. I congratulated him and that earned him more social drinking sprees. In the taped audio conversations recorded by the nurse, patients gave him the impression that they approved of his performance, whereas they had been critical of him when talking to me. Of course, the patients could not say anything negative about him to him for fear of facing unfair reception. His action was not absurd but served as a way for me to understand how patients may hide their real feelings about their consultants and the clinic. It is always good to use gatekeepers as springboards for the first encounters but it is better to gradually detach from them and establish a network of relationship with research participants. Gatekeepers become constrains as their value may get exhausted as the research develops. Each of them has a vital role to play at a given place and time given that some doors, which are open to you, are closed to them.

\section{Insider and outsider dilemma in fieldwork}

My fieldwork is the type that Anthropologists describe as doing fieldwork 'at home'. ${ }^{9-13,20}$ It is the type that portrays me as both an 'insider' and an 'outsider'. ${ }^{19,34}$ What is important is what I did, how I did it, whether I did it according to anthropological tradition and the end product. I was an 'insider' as a Cameroonian working in Yaounde, where I lived and in Bafut, one of the Grassfield Kingdoms with which my own cultural area by birth had much in common. But I was an 'outsider' as a social scientist ${ }^{19}$ enquiring into indigenous medical conceptions and also an 'outsider' in the places where fieldwork was conducted by virtue of my birth and cultural identity. Most clinic staff who knew my social position considered me as an 'outsider'. Others who initially considered me as an 'insider' changed their idea as they subsequently understood what I was doing. I was a stranger in this land and had to negotiate access like anyone who had no previous links there. The way I presented myself, the role that I played and my interaction with people, contributed greatly in the field. Even though objectivity is never total, sympathizing with people is an aspect that an anthropologist can risk undermining if he goes completely native, ${ }^{35}$ forgetting to apply anthropological principles. ${ }^{36}$ I look at these scenarios and see people, occasions, products, patterns of behavior that I have been seeing all my life. I see them as obvious to me as an insider and at the same time see what is new to me even though an insider. This places me in a position of an outsider.

In ordinary terms an outsider is an external expert, researcher, observer, stranger to the local context, providing an ethic perspective to the research and data needs. On the other hand an insider is a local, native of the place; a researcher, comfortable and familiar with the socio-cultural context, informing the research process with an 
insider's view and knowledge if not quite providing, but supporting the emic worldview that would emerge. There is a lot in understanding a culture or a society from the inside. What remains arcane to the external researcher suddenly becomes clear in the presence of an insider. However, a researcher completely removed from the research context, brings to an ethnographic study, remain the issue at stake during fieldwork. The person called outsider because he is a stranger makes one to understand the value of an outsider's perspective in ethnographic research. Feldman-Savelsberg ${ }^{37}$ recently demonstrated in her work on Cameroon how photographs and thoughts from village to urban and Diaspora life and everyday experiences of Cameroon and with Cameroonians provide insides into the field. Her initial work in Cameroon as a peace corp volunteer in the 1980s and later as an ethnographer in the 1990s transformed her from being an outsider into being an insider. She provided interesting insights emerging from her fieldwork.

And that is the difference between an "outsider" and an "insider" in ethnographic research. It is looking at the everyday, the mundane and the normal with fresh eyes. As a local "expert" sometimes we tend to take things for granted; or ignore the more obvious and the ordinary in the course of our research. Whereas, ideally the ethnographer looks at all that is in and produced by the human sphere or behavior as "anthropologically strange". The insider and outsider roles are all important in the field. Each of them contributes equally. ${ }^{34}$ It is, therefore, not alright to claim that the outsider notices, picks up and questions the obvious and the insider inquires, digs up more from memory and past understanding and explains. Irrespective of what the researcher's origins are, he/she needs to play the role of both an outsider and insider in the course of ethnographic inquiry. Insider and outsider roles are usually dynamic. At one period of your fieldwork, you are an insider and in another you are an outsider. Being an outsider or insider does not matter whether you are a native or a stranger both in terms of your place of origin, your profession and familiarity with people and events. You assume any of these roles as opportunities emerge during fieldwork. Insider status is how potentially volatile it is. Insideness is not fixed but shifts to outsideness according to those with whom a researcher interacts and the social and cultural context of the encounters.

\section{Urban and rural fieldwork relationships}

I used participant observation in conducting fieldwork, which entailed studying the urban and the rural. Once, anthropology was associated with study of 'primitive' societies. A study like mine studying both a rural and urban capital, contributes to the rethinking that has been going on in anthropology for many years about the nature of the discipline today. The neglect of studying urban phenomena is gradually being broken and my looking at the two environments lends credit to this work as another step towards comparatively analyzing the complex order of the urban and rural societies.

I have put into practice the challenge that faces the conduct of ethnographic fieldwork in urban settings comparing with the rural. My experience can be improved on in subsequent comparative rural/urban fieldwork. I did not set out to do fieldwork differently in about two million inhabitants of Yaounde or the more than 400000 inhabitants of Biyem-Assi. The intensity of the fieldwork might have differed but I tried to use the same approach in both the urban and rural health districts. It happened that my choice of a rural health district (Bafut) was one where the population is relatively homogenous, hence this permitted me to study issues of ritual life and interact more in a wider community than was the case in the urban health district of BiyemAssi in Yaounde. I chose Bafut and Yaounde because these were the only two settings that provided Primary Health Care (PHC) to diabetes patients at the time.

A greater majority of the residents of cities come from some rural area and bring their cultures into the city. Culture is a continuous umbilical cord that links urbanites to their villages or tribes. When these cultures meet in town, they undergo transformations and new cultures emerge, for example amongst socio-professional and ethnic groups. At the same time, urban characteristics are spilling over into rural areas. My urban and rural comparative approach portrays the beliefs, understanding and behaviors that people in urban and rural areas have and share about cultural issues. These might not necessarily show a clear demarcation from a bird's eye-view, but closer attention shows that culture in the context of an illness carries a lot of meaning with it. I did not focus on any specific ethnic group to conduct fieldwork in Yaounde or in Bafut but selected diabetes patients receiving care in the four facilities that were offering PHC and their families. If anthropological fieldwork does not step aside and reinforce urban ethnography, some of the problems of urban areas will be less understood and will remain unresolved. Health issues cut across cultures and need to be understood from both rural and urban perspectives so that solutions to the illnesses and infectious and chronic diseases can be more broad-based.

Although I am a Cameroonian and a grassfield person, over the years I became simultaneously of another place as well, a child of anthropology. This combination of birthrights has produced an interesting complexity that the less observant might mistake for a dilemma.

In the study, I was always tempted to draw on assumptions and comparisons with what I knew about my own ethnic culture, which most of the time turned out to be contrastingly different. Doing my ethnographic work in my home country was a privilege which did not bring about a subjective stance but, on the contrary, made me better able to probe more deeply into what could otherwise seem obvious and so go beyond what a foreign observer could explore. Previous to my work, Van Ginkel ${ }^{38}$ had commented on the aspect of Endoethnography as being rewarding when anthropologist consider the perspectives of the people whom they study in their ethno-analysis.

Most ethnographic studies in Sub-Sahara Africa have been rural based ${ }^{9,17,39-42}$ with very few urban ones ${ }^{43}$ but mine has considered the two settings. Feldman-Savelsberg ${ }^{37}$ has comparatively studied a community in Cameroon in their place of origin, followed the people to the city and in the Diaspora to comprehend the dynamics in their lives as they move further from home. It is a way of understanding a people's life as the change places and your role as an anthropologist as you toggle between outsider and outsider roles. This comparative approach, even though very challenging is actually the most rewarding because of the amount of ethnography that it produced, ushering in a new perspective.

\section{Conclusion}

Language problems seem to be one of the main challenges for conducting fieldwork in all cultures. This needs to be taken into account during preparing to start ethnographic fieldwork. Much has been written about doing anthropology at home from the developed countries of Europe and America but though this study underlines the main issues similarly with what European ethnographers have 
highlighted, differences obtain within the African or non-western context. This is due mainly because of the cultural differences existing between the two in representing home and other. It is worthy of acknowledging strangeness beyond language and fitting it within the context of home cultures to which we are aliens. Whatever approach a researcher takes, it is important that 'outsiders' feel just as competent and accepted as 'insiders,' and vice versa, in making their contributions on the chosen subject of inquiry. This is because every researcher's insight help to see the full picture and more clearly too. Without both insiders and outsiders making their perspectives, the narrative will never be completed. We can have a wider view of issues by having a wider variety of voices. Competing groups and individuals may have limited access to reality but the variety of voices that echo the reality will widen the scope of knowledge obtained and reported. Strangeness disappears during fieldwork and the writing of the ethnography resulting from fieldwork. Outsiders should realize that their perspectives and contributions to ethnography is relevant and significant. The best way to overcome the assigned strangeness is endeavoring to know, respect and understand a people and their culture by immersing themselves into the culture, learning the language and shading the traits of biases. ${ }^{44,45}$

\section{Acknowledgements}

None.

\section{Conflict of interest}

Author declares there is no conflict of interest in publishing the article.

\section{References}

1. Naidoo L. Ethnography: An Introduction to Definition and Method. An Ethnography of Global Landscapes and Corridors, INTECH, Croatia. 2012. p. $1-8$.

2. Hammersley M, Atkinson P. Ethnography Principles in Practice. Cambridge University Press, UK; 1983. p. 26.

3. Atkinson P, Hammersley M. Ethnography and Participant Observation. In: Denzin NK, Lincoln YS, editor. Handbook of Qualitative Research, Thousand Oaks, USA; 1994. p. 248-260.

4. Magnusdottir H. Overcoming strangeness and communication barriers: a phenomenological study of becoming a foreign nurse. Int Nurs Rev. 2005;52(4):263-269.

5. Kahn DL. How to conduct research. In: Cohen MZ, et al. editor. Hermeneutic Phenomenological Research: A Practical Guide for Nurse Researchers. Sage, USA; 2000. p. 57-70.

6. Meadows LM, Morse JM. Constructing evidence within the qualitative project. In: Morse JM et al. editor. The Nature of Qualitative Evidence, Sage, USA; 2001. p. 187-200.

7. Awah PK. An ethnographic study of diabetes: implications for the application of patient centred care in Cameroon. Journal of Anthropology. $2014 ; 1-12$.

8. Ellen RF. Ethnographic Research: a guide to general conduct. Academic Press, UK; 1984;403.

9. Pool R. Dialogue and the Interpretation of Illness: Conversation in a Cameroon Village. 1st ed. Explorations in Anthropology. Bloomsbury Academic, USA; 1994. p. 298.

10. Hadolt B. Locating difference: A medical anthropology 'at home'? Anthropol Med. 1998;5(3):311-323.

11. Fainzang S. Anthropology at home via anthropology abroad: The problematic heritage. Anthropol Med. 1998;5(3):269-277.
12. Reis R. Resonating to pain: Introspection as a tool in medical anthropology 'at home'. Anthropology \& Medicine. 1998;5(3):295-310.

13. Dongen VE and Fainzang S. Editorial: Medical anthropology at home: Creating distance. Anthropology \& Medicine. 1998;5(3):245-250.

14. Gardner K. Location and relocation: Home 'The field' and Anthropological Ethics. In: Watson CW, editor. Being There, Fieldwork in Anthropology, Pluto Press, UK; 1999. p. 49-73.

15. Watson CW. Introduction: The quality of being there. In: Watson CW, editor. Being There, Fieldwork in Anthropology, Pluto Press, UK; 1999. p. $1-24$.

16. Rosaldo R. Culture and Truth: The Remaking of Social Analysis. Beacon Press, USA; 1989. p. 247.

17. Goheen M. Men Own the Field, Women Own the Crops: Gender and Power in the Cameroon Grassfields. The University of Wisconsin Press, USA; 1996. p. 280.

18. Gufler H. Affliction and Moral Order: Conversation in Yambaland. CSAC Monograph, Africa; 2003.

19. Young M. In the Sticks: Cultural Identity in a Rural Police Force. Clarendon Press, UK; 1993. p. 322.

20. Pierano MGS. When Anthropology is at home: The different context of a single discipline. Annu Rev Anthropol. 1998;27:105-128.

21. Kuwanyama T. Natives as dialogic partners: Some thoughts on native anthropology. Anthropology Today. 2003;19(1):8-13.

22. Merton RK. Insiders and Outsiders: A Chapter in the Sociology of Knowledge. American Journal of Sociology. 1972 ;78(1):9-47.

23. Hutchinson S. Coping with Money, War, and the State. Nuer Dilemmas, University of California Press, USA; 1992. p. 420.

24. Dongen VE. Strangers on terra cognita: Authors of the other in a mental hospital. Anthropology \& Medicine. 1998;5(3):279-293.

25. Awah P, Phillimore P. Diabetes, Medicine and Modernity in Cameroon. Africa; 2008;78(4):475-495.

26. Sandelowski M. Focus on qualitative methods: sample size in qualitative research. Res Nurs Health. 1995;18(2):179-183.

27. Smith LT. Decolonizing methodologies: Research and indigenous peoples. Otago University Press, UK; 1999. p. 200.

28. Dillard CB. When the ground is black, the ground is fertile. In: Denzin $\mathrm{NK}$, et al. editor. Handbook of critical and indigenous methodologies, Sage, USA; 2008. p. 277-292.

29. Gupta C, Kelly AB. The Social Relations of Fieldwork: Giving back in a research setting. Journal of Research Practice. 2014;10(2):1-11.

30. CIOMS. International Ethical Guidelines for Biomedical Research Involving Human Subject. Bull Med Ethics. 2002;182:17-23.

31. Canales MK. Othering: toward an understanding of difference. ANS Adv Nurs Sci. 2000;22(4):16-31.

32. Gupta C, Chattopadhyaya DP. Introduction. Cultural Otherness and Beyond. Brill, USA; 1998. p. 1-42.

33. Gregory E. Learning to Read in a New Language: Making Sense of Words and Worlds. Sage publishing, UK; 2008. p. 256.

34. Naaeke A, Kurylo A, Grabowski M, et al. Insider and Outsider Perspective in Ethnographic Research. Proceedings of the New York State Communication Association. 2011;2010(9):153-160.

35. Shusterman R. Understanding the self's other. In: Gupta G, Chattopadhyaya DP, editor. Cultural Otherness and Beyond, Brill, USA; 1998. p. 107-114.

36. Hammersley M, Atkinson P. Ethnography: Principles in Practice. Tavistock Publications, USA; 2007. p. 1-25. 
37. Savelsberg FP. Reproducing Belonging between Africa and Europe. Mothers on the move, The University of Chicago Press, USA; 2016. p 280 .

38. Ginkel VR. The repatriation of anthropology: Some observations on Endo-ethnography. Anthropol Med. 1998;5(3):251-267.

39. Kaberry MP. Women of the Grassfields. HMSO, UK; 1952. p. 218.

40. Nkwi NP. Cameroon Grassfield Chiefs and Modern Politics. Paideuma. 1979;25:99-115.

41. Rowlands JM, Warnier JP. Sorcery, Power and the Modern State in Cameroon. Man. 1988;23(1):118-132.
42. Edgard KK. Muth and Political Economy in Bafut (Cameroon): The Structural History of an African Kingdom of Bafut. Paideuma. 1989;34:49-89.

43. Sanjek R. Urban Anthropology in the 1980s: A World View. Annual Review of Anthropology. 1990;19:151-189.

44. The National Commission for the Protection of Human Subjects of Biomedical and Behavioural Research. The Belmont Report Ethical Principles and Guidelines for the Protection of Human Subjects of Research, USA; 1979.

45. Savelsberg FP. Reproducing Belonging between Africa and Europe. Mothers on the move, The University of Chicago Press, USA; 2016. p. 280 . 